\title{
Educating for Health Equity: Walking the Walk
}

"Transforming education to strengthen health systems in an interdependent world" is the subtitle to a report by a global commission on health professional education, Health Professionals for a New Century (HPNC). The report aspires to do for health professional education in this century what Flexner did for medical education in the last-spark a revolution.[1] And indeed a necessary one if we are to see global health equity in practice, not simply in print.

In this issue of MEDICC Review, our authors examine several aspects of the continuing transformation of health professional education in Cuba, for both Cuban and international students. The country's consistent investment in developing committed human resources for health-even in the worst financial times-has been key to continuous improvement of population health outcomes and, increasingly, to the sustainability of its universal health system. This experience also offers a fascinating demonstration that political will may play a more essential role than economic resources when it comes to attaining health equity.

The quest for global health equity and the changing paradigms of medical education necessary for its achievement was the subject of a MEDICC Review issue almost four years ago. In revisiting the topic, we expand the domain to include health professions education for leadership more generally, consistent with current emphasis on a multiprofessional perspective and professional values.

A major Cuban contribution to global health equity is of course the Latin American Medical School (ELAM, the Spanish acronym), which has already graduated several thousand young physicians from developing countries and underserved communities worldwide. In this issue, senior editor Conner Gorry describes an initiative to monitor ELAM graduates' impact on health outcomes, systems and policy. She reports on graduates' projects she has visited in their home countries, as well as on the formidable obstacles they face (Cuba's Latin American Medical School: Can Socially-Accountable Medical Education Make a Difference?).

Original research by Quintana is at the intersection of instructional and institutional reform in medical education. Rector of the Medical University of Villa Clara, he "walks the walk," taking a frank look at his university's program to enrich the competencies of South African medical students (Assessment of a Complementary Curricular Strategy for Training South African Physicians in a Cuban Medical University). Pernas' Perspective argues for reform in the basic sciences portion of Cuba's medical curriculum to make its content more relevant to clinical practice (Changes Needed in Basic Biomedical Sciences Teaching in Cuban Medical Schools).

Also in the arena of health professional education, two articles touch on another HPNC central theme, the contention that "the core space of every health system is occupied by the unique encounter between one set of people who need services and another who have been entrusted to deliver them." This trust, says the report, "is earned through a special blend of technical competence and service orientation, steered by ethical commit-
Cuba has lost a medical giant, Dr Rubén de los Ángeles Rodríguez Gavaldá, the "father of Cuban allergology." The renowned allergist and pediatric immunologist who introduced the principles of immunology to Cuba in 1967 and founded two children's hospitals, died in June at age 97. Sorely missed will be his legendary expertise, kind heart and the twinkle in his eyes when describing allergists as "medicine's great detectives." We dedicate this issue of MEDICC Review to Dr Rodríguez and extend our condolences to his family, friends and colleagues.

ment and social accountability." Hodelín's Perspective reflects on why training in bioethics is critical to preparing health professionals for such socially-accountable leadership (Contributions of Bioethics to Health Sector Leadership); and González argues passionately in his Viewpoint that a sense of calling to service is fundamental to the quality of health care (The Vocation to Serve: Cornerstone of Health Care).

Martínez's article, while not addressing instructional or institutional reform as such, is certainly relevant to both, dealing as it does with important aspects of institutional and individual capacity building for health systems research in one of the professions most often lacking in these skills in Cuba (Developing Nursing Capacity for Health Systems and Services Research in Cuba).

In other research, Abdo reports results of extracorporeal blood purification as supportive therapy in one of medicine's most challenging clinical populations (Continuous Venovenous Hemodiafiltration in Patients with Multiple Organ Dysfunction Syndrome in an Intensive Care Unit) and Gómez shares early work on a scale for predicting failure of stem cell therapy for lower limb ischemia (Possible Predictors of Poor Angiogenesis after Hematopoietic Stem Cell Autograft for Lower Limb Ischemia). Finally, Triana extracts lessons from a field experience in international medical cooperation, with interesting notes on the role of social determinants in surgical recovery (Cataract and Pterygium Surgery Results in Venezuelan Patients Treated in the Misión Milagro Program).

With this issue we welcome several new members to MEDICC Review's Editorial Board: Neil Arya and Noni MacDonald (both of Canada), Michael Bird (Santo Domingo-San Juan Pueblo, USA), Paulo Buss (Brazil), Suwit Wibulpolprasert (Thailand) and Paul Worley (Australia). We are pleased and proud to add these distinguished professionals to the board, bringing even greater depth and diversity to the mix of expertise and wisdom that we rely upon to enhance the journal's quality and relevance, and to ensure that we give it our best. -1 -

\section{The Editors}

1. Frenk J, Chen $L$ and The Commission. Health professionals for a new century: transforming education to strengthen health systems in an interdependent world. Lancet 2010 Dec 4;376:1923-58. 